\title{
PREVALENCE OF TAKAYASU'S ARTERITIS IN RIO DE JANEIRO (PREVTAKRIO): A POPULATION-BASED STUDY
}

\author{
Matheus Vieira'1,2,*, Manuella Ochtrop³, Flávio Sztajnbok²,3, Camila Souto ${ }^{3,1}$, José Fernando Verztman4, Blanca Bica², Rozana \\ Ciconelli ${ }^{1}$, Alexandre Wagner Silva de Souza ${ }^{1}$ \\ 1.Universidade Federal de São Paulo, São Paulo (SP), Brazil; 2.Universidade Federal do Rio de Janeiro, Rio de Janeiro (RJ), Brazil; 3.Universidade \\ do Estado do Rio de Janeiro, Rio de Janeiro (RJ), Brazil. 4.Hospital dos Servidores do Estado do Rio de Janeiro, Rio de Janeiro (RJ), Brazil \\ *Corresponding author: matheusvieira91@gmail.com
}

\section{BACKGROUND}

Takayasu's arteritis (TAK) is a large-vessel vasculitis typically affecting subjects under the age of 40 . Although progressively recognized as having worldwide distribution, geographical variations are striking. Outside high-prevalent countries, TAK's prevalence is reported to range between 4.7-13.2 cases/million inhabitants. So far, few population-based studies have been performed, and to date, Brazilian epidemiological data come from tertiary centres where TAK figures as one of the most frequent vasculitis in the Southeast region.

\section{METHODS}

Cross-sectional field research where rheumatologists and angiologists working in both public and private services in Rio de Janeiro were invited to complete an online REDCap survey in case they followed TAK patients on a regular basis. Takayasu's arteritis patients should be living in Rio (6,747,815 inhabitants) and fulfil EULAR-PRINTO-PRES criteria ( $<18$ years old), ACR 1990 or modified Ishikawa criteria ( $\geq 18$ years old). Duplicate patients or those living outside the city were excluded. Prevalence was calculated as the number of cases/million inhabitants. The mean annual incidence over the last decade was estimated. Comparisons were performed regarding the service of provenance and skin colour.

\section{RESULTS}

Between May 2020 and May 2021, more than 250 doctors were contacted, and 32 of them contributed with 134 patients. After exclusions, 114 cases were analysed yielding a prevalence of 16.9 cases/million inhabitants (95\% Cl 14.1-20.3). The mean incidence between 2010-2019 was 0.94 cases/million inhabitants/year (95\%Cl 0.73-1.21). Ninety-seven (85.1\%) patients were female, with a female:male ratio of 5.7:1.0. The most frequent skin colour was white (44.7\%), followed by brown (33.3\%) and black (16.7\%). The relative prevalence of TAK in women and black individuals was $27.0(95 \% \mathrm{Cl} 22.2-33.3)$ and $25.1(95 \% \mathrm{Cl} 16.1-39.3)$ cases/million, respectively. Mean age at symptom onset and diagnosis was $27.1( \pm 13.9)$ and $31.6( \pm 14.6)$ years, respectively. The median interval between symptom onset and diagnosis was 1 [IQR 0-5] year. Juvenile onset ( $<18$ years) was seen in $35(30.7 \%)$ patients, while symptoms onset after 40 years occurred in 20 (17.5\%). Ninety-one (79.8\%) patients were followed-up in public services and ACR criteria was the most applied (74.5\%). Patients followed in public services had earlier symptoms onset than those followed in private care $(25.1 \pm 13.0$ vs. $35.1 \pm 14.5$ years, $p=0.002)$, while white patients had latter onset as compared to non-white ones $(30.8 \pm 14.4$ vs. $24.0 \pm 12.9$ years, $p=0.01$ ).

\section{CONCLUSION}

In this largest population-based study on TAK epidemiology to date, Rio de Janeiro presents one of the highest prevalence in the world. Women and blacks seem more affected than the general population.

\section{KEYWORDS}

Takayasu’s arteritis, Large-vessel vasculitis, Epidemiology, Prevalence, Incidence. 